Canadian

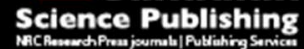

Canadian Journal of Chemistry Revue canadienne de chimie

\title{
Synthesis of amphiphilic ABA triblock oligomer via ATRP and its surface properties
}

\begin{tabular}{|r|l|}
\hline Journal: & Canadian Journal of Chemistry \\
\hline Manuscript ID & cjc-2016-0591.R1 \\
\hline Manuscript Type: & Article \\
\hline Date Submitted by the Author: & $26-$-Dec-2016 \\
\hline Complete List of Authors: & $\begin{array}{l}\text { Wang, Lei; Soochow University, College of Textile and Clothing Engineering } \\
\text { Wen, Shaoqing; Soochow University, College of Textile and Clothing } \\
\text { Engineering } \\
\text { Li, Zhanxiong ; Soochow University, College of Textile and Clothing } \\
\text { Engineering }\end{array}$ \\
\hline Keyword: & \begin{tabular}{l} 
Amphiphilic triblock oligomer, Fluoroalkyl, ATRP, Surface properties \\
\hline
\end{tabular} \\
\hline
\end{tabular}

SCHOLARONE ${ }^{m}$

Manuscripts 


\title{
Synthesis of amphiphilic ABA triblock oligomer via ATRP and its surface properties
}

\author{
Lei Wang ${ }^{\mathrm{a}, \mathrm{b}}$, Shaoqing Wen ${ }^{\mathrm{a}, \mathrm{b}}$, Zhanxiong $\mathrm{Li}^{\mathrm{a}, \mathrm{b}, *}$ \\ ${ }^{a}$ College of Textile and Clothing Engineering, Soochow University, Suzhou 215021, \\ China \\ ${ }^{\mathrm{b}}$ National Engineering Laboratory for Modern Silk, Suzhou 215123, China
}

\begin{abstract}
A series of novel amphiphilic ABA-type poly (tridecafluorooctyl acrylate) - poly (ethylene glycol)-poly (tridecafluorooctyl acrylate) ( $p$-TDFA-PEG- $p$-TDFA) triblock oligomers were successfully synthesized via Atom Transfer Radical Polymerization (ATRP) using well-defined Br-PEG-Br as macroinitiator and copper as catalyst. The block oligomers were characterized by Fourier Transform Infrared (FT-IR) spectroscopy, ${ }^{1} \mathrm{H}$ and ${ }^{19} \mathrm{~F}$ Nuclear Magnetic Resonance (NMR). Gel Permeation Chromatography (GPC) text showed that the block oligomers have been obtained with narrow molecular weight distributions of 1.22 to 1.33 . X-ray Photoelectron Spectroscopy (XPS) was carried out to confirm the attachment of $p$-TDFA-PEG- $p$-TDFA onto the silicon substrate, together with the chemical compositions of $p$-TDFA-PEG- $p$-TDFA. The wetabilities of the oligomer films were measured by water contact angles (CA). Water contact angles (CA) of $p$-TDFA-PEG- $p$-TDFA film were measured and its' morphologies were tested by
\end{abstract}

\footnotetext{
* Corresponding author at: Soochow University, College of Textile and Clothing Engineering, No. 199 Renai Road, Industry Park, Suzhou, China.

Tel: +86-512-67061190; Fax: +86-512-67246786.

E-mail address: lizhanxiong@suda.edu.cn (Z. Li).
} 
Atomic Force Microscopy (AFM). The result showed that the contact angles of the oligomer films, which possess fluoroalkyl groups assembled on the outer surface, increase after heating due to the migration of fluoroalkyl groups and the resulted microphase separation of the $p$-TDFA-PEG- $p$-TDFA.

KEYWORDS: Amphiphilic triblock oligomer; Fluoroalkyl; ATRP; Surface properties

\section{INTRODUCTION}

Copolymers obviously result from the polymerization of more than one (usually two) monomer. Amphiphiles are compounds which composed of hydrophilic and hydrophobic parts. These molecules that come to mind as being amphiphiles belong to be the classes of surfactants and lipids. Amphiphilic block copolymer could endow the surface dual nature with a compositional and morphological complexity due to its well-defined structure. ${ }^{1-5}$ Fluorinated polymers present excellent water and oil repellency because of the low polarizability and the strong electronegativity of the fluorine atom. Among various fluorinated materials, fluorinated polyacrylates have appeared as the most widely used hydrophobic coatings of textiles. ${ }^{6-12}$ Moreover, many previous publications indicated that the fluorinated units can effectively facilitate the surface coverage of a high-energy hydrophilic groups (such as PEG), which results in excellent fouling resistance for amphiphilic systems. ${ }^{13-18}$ Therefore, preparation of such copolymers with well-defined structure is of great significance for application. Synthesis of block polymers, which only limited by synthetic tools and 
conditions in the 20th century, has recently received more attention during the development of controlled/living radical polymerization. For instance, in the past, block copolymers with appropriate functionality can be achieved with cationic, anionic or other limited types of monomer chains, often requiring controlling experimental conditions strictly, under the conditions in the absence of water or oxygen. Fortunately during the last decades, significant progress had been made in the area of controlled/living radical polymerization. This reaction gradually relaxed in control of the experimental conditions and allowed a controllable structure of aimed products. There are many researches about the synthesis of amphiphilic block copolymers via controlled polymerization in recent years. ${ }^{19-22}$ The major controlled/living radical polymerization techniques include Stable Free Radical Polymerization (SFRP), ${ }^{23-25}$ Reversible Addition-Fragmentation Chain Transfer polymerization (RAFT), ${ }^{26-29}$ and Atom Transfer Radical Polymerization (ATRP). ${ }^{30-32}$ ATRP has proved to be a very robust and versatile controlled/living free radical process, ${ }^{33-36}$ which can be catalyzed by transition metal complexes, such as $\mathrm{CuX}$ or other metal complexes with copper, nickel, palladium, ruthenium and rhodium. Meanwhile, the ATRP method has been proven effective for a wide range of monomers (styrene, acrylate, acrylonitrile, etc.) in a variety of solvents (benzene, water, etc.) under mild reaction conditions. ${ }^{37-39}$ In addition, compared with other traditional polymerization methods, ATRP can lower the molecular weight distribution of a producing copolymer and improve the controllability of polymerization. ${ }^{40,41}$ Therefore, ATRP has become an important method of designing 
polymers of various architectures, such as di/triblock copolymers, ${ }^{42-47}$ star-shaped copolymers ${ }^{48-51}$ and comb-shaped copolymers, ${ }^{52}$ etc.

In this study, we attempted to synthesis a series of novel amphiphilic ABA triblock oligomers, namely poly (tridecafluorooctyl acrylate)- poly (ethylene glycol)-poly (tridecafluorooctyl acrylate) ( $p$-TDFA-PEG- $p$-TDFA) by ATRP with different chain-lengths. Firstly the macroinitiator Br-PEG-Br was prepared from PEG with two radical hydroxide groups and 2-Bromoisibutyryl Bromide. Subsequently, the macroinitiator reacted with $3,3,4,4,5,5,6,6,7,7,8,8,8$-Tridecafluorooctyl acrylate (TDFA) by ATRP. It was expected, by means of changing the ratio of Br-PEG and fluoroacrylate, to control the molecular weight of synthetic product. The properties of the oligomers films were examined by using Gel Permeation Chromatography, X-ray photoelectron spectroscopy, contact angle measurement, and atomic force microscopy.

\section{EXPERIMENTAL}

\section{Materials}

3,3,4,4,5,5,6,6,7,7,8,8,8-Tridecafluorooctyl acrylate (TDFA, Suzhou Bo Chemical Technology Co., Ltd, 99\%) was washed with 5\% aqueous $\mathrm{NaOH}$ solution to remove any inhibitor, and was then distilled under reduced pressure prior to use. N,N,N',N",N"-pentamethyldiethylene triamine (PMDETA, Shanghai Aladdin Reagent, 99\%), 2-Bromoisobutyryl bromide (BriB-Br, Shanghai Aladdin Reagent, 98\%), Poly (ethylene glycol) (PEG, MW=600 g/mol) were used as received. PEG 
obtained from fluka was dried by azeotropic distillation with toluene under dry nitrogen atmosphere and used immediately. Triethylamine (TEA) was dried by $\mathrm{CaH}_{2}$ overnight, and then distilled under reduced pressure before use. Tetrahydrofuran (THF) was dried and fractionally distilled over sodium wire in the presence of benzophenone. Cuprous bromide (CuBr, Shanghai Aladdin Reagent, 98\%) was purified by stirring overnight over acetic acid at room temperature, followed by washing the solid with ethanol and diethyl ether prior to drying at $50{ }^{\circ} \mathrm{C}$ under vacuum for 1 day.

\section{Measurements}

FT-IR was performed with a 5700 Fourier transform infrared spectrometer (Nicolet, US). The wavenumber range was controlled between 4000 and $500 \mathrm{~cm}^{-1}$ at a resolution of $4 \mathrm{~cm}^{-1}$. All original spectra were baseline corrected using the Omnic 6.1 software. ${ }^{1} \mathrm{H}$ and ${ }^{19} \mathrm{~F}$ nuclear magnetic resonance (NMR) spectra were recorded by using a Bruker spectrometer operating at $400 \mathrm{MHz}$ (Varian, US), with samples be dissolved in $\mathrm{CDCl}_{3}$. Chemical shifts $(\delta)$ were given in ppm using tetramethylsilane (TMS) as internal reference. Gel permeation chromatography (GPC, Viscotek TDA 302) was used for measuring the molecular weight and polydispersity index, and THF was used as the eluent with a flow rate of $1.0 \mathrm{~mL} / \mathrm{min}$ at room temperature. XPS measurements were carried out using a Kratos Axis Ultra HAS photoelectron spectrometer (Shimadzu, Japan) which equipped with a monochromatic Al Ka X-ray source $(\mathrm{h} v=1486.6 \mathrm{eV})$ at $12 \mathrm{kV}$ and $15 \mathrm{~mA}$ using an analyzer pass energy of $20 \mathrm{eV}$. The bare pressure in the chamber was maintained at $4.0 \times 10^{-9} \mathrm{~Pa}$ during the measurement, and spectra were connected at room temperature. The photoelectron 
takeoff angle to the surface normal was set at $30^{\circ}, 60^{\circ}$ and $90^{\circ}$, respectively. The full widths at half-maximum (fwhm) of each component were constrained to $0.9-1.3 \mathrm{eV}$. The binding energy scale is referenced to the aliphatic saturated hydrocarbon $\left(\mathrm{CH}_{2}\right)$ peak at a binding energy of $285.0 \mathrm{eV}$ to compensate for sample charging. The error in defining the position of peaks was estimated at about $0.1 \mathrm{eV}$. CA measurements were carried out on silicon substrates in order to investigate the changes of water repellency; it was measured with an optical contact angle goniometer (OCAH 200, Dataphysics Inc.) at room temperature and ambient humidity. Water was used as the liquid for the analysis using the sessile droplet method, and the volume of each liquid droplet was 3 $\mu \mathrm{L}$. The CA values reported were the averages of five separate measurements made on different areas of the substrates surfaces, and the experimental errors of the measurements were within $\pm 2^{\circ}$. AFM studies were carried out using a MultiMode Nanoscope IIIa (Digital Instruments, Veeco, USA). Tapping Mode was chosen in order to minimize surface deformation; images were displayed and analyzed using the Nanoscope software from Digital Instruments (Version 8.0). Height images are plane-fit in the fast scan direction with no additional filtering operations. The scan size is $2 \mu \mathrm{m} \times \mu \mathrm{m}$.

\section{Preparation of Br-PEG-Br Macroinitiator}

Three fluorine-containing oligomers were synthesized via Atom Transfer Radical Polymerization in two steps (see Scheme 1). The ATRP macroinitiator was prepared according to literature ${ }^{46}$. Under dry nitrogen atmosphere, Poly (ethylene glycol)-600 (PEG-600) (12.0 g, $20 \mathrm{mmol}$ ) was dissolved in dry THF $(60 \mathrm{~mL})$, followed by adding 
excess dry triethylamine $(10.1 \mathrm{~g}, 100 \mathrm{mmol})$ as the acid-trapping agent and then cooled to $0{ }^{\circ} \mathrm{C}$. 2-Bromoisobutyryl bromide $(11.04 \mathrm{~g}, 48 \mathrm{mmol})$ in dry THF $(30 \mathrm{~mL})$ was then added dropwise to the above solution over $1 \mathrm{~h}$. After addition, the solution was allowed to warm up to ambient temperature and was stirred for $24 \mathrm{~h}$. After the reaction was complete, the mixture was filtered to remove the solid, and the filtrate was evaporated under reduced pressure to obtain a viscous light brown liquid as the crude product. After dissolved in ethyl acetate, the solution was washed 3 5 times by distilled water, then dried with anhydrous magnesium sulfate. The solution was evaporated under reduced pressure to remove ethyl acetate and finally obtained a yellowish transparent liquid as the macroinitiator.

\section{Synthesis of amphiphilic ABA triblock oligomer via ATRP}

The amphiphilic triblock oligomer $p$-TDFA-PEG- $p$-TDFA was synthesized via ATRP by using the macroinitiator (Br-PEG-Br), the catalyst $(\mathrm{CuBr})$ and the ligand (PMDETA). The molar ratio of [TDFA]/[Br-PEG-Br]/[CuBr]/[PMDETA $]$ was $8 / 1 / 2 / 2,10 / 1 / 2 / 2$ and $12 / 1 / 2 / 2$, and a typical polymerization procedure was as follows: First, 3 mmol Br-PEG-Br macroinitiator, $6 \mathrm{mmol} \mathrm{CuBr}$ and 6 mmol PMDETA were added to a dried three-neck flask. The flask was degassed by three freeze-vacuum-thaw cycles and filled with dry nitrogen. For the deoxygenated system, a solution of $24 \mathrm{mmol}$ TDFA in $30 \mathrm{~mL}$ THF was injected via syringe, then the three-neck flask was transferred to an oil bath held by a thermostat at the desired temperature of $90^{\circ} \mathrm{C}$ to polymerize for $21 \mathrm{~h}$ under vigorously stirring. After the reaction was finished, the flask was naturally cooled to room temperature. The 
unreacted TDFA and solvent was removed under reduced pressure, and then the residue was redissolved in THF and centrifuged to remove insoluble material $(12,000$ $\mathrm{rpm} \times 10 \mathrm{~min})$. The supernatant was passed through a neutral alumina column to remove the remaining copper catalyst. The crude polymer residue was purified by precipitation $(2 \times)$ from $n$-hexane and washed with water $(6 \times 40 \mathrm{~mL})$. After drying at $60^{\circ} \mathrm{C}$ under vacuum for $24 \mathrm{~h}$, a viscous pale yellow material was obtained as the end product.

\section{Oligomer Film Preparation}

P-TDFA-PEG-p-TDFA was dissolved in ethyl acetate at $10 \%(\mathrm{w} / \mathrm{v})$ solution concentration. Then the solution was dropped on silicon wafers by using a Cee model $100 \mathrm{CB}$ spin coater at $2500 \mathrm{rpm}$ for $2 \mathrm{~min}$ to get the oligomer films. These samples were allowed to place at room temperature for $2 \mathrm{~h}$ in order to remove the solvent.<smiles>CC(O)COC(C)(C)[18OH]</smiles><smiles>CC(C)(Br)OC(=O)C(C)(C)OCC(=O)C(C)(C)Br</smiles><smiles>C=CC(=O)OCCC(C)(C)C(F)(F)F</smiles>

Scheme 1 Synthetic routes of $p$-TDFA-PEG- $p$-TDFA by ATRP 


\section{RESULT AND DISCUSSION}

\section{FT-IR, ${ }^{1}$ H NMR and ${ }^{19}$ F NMR spectroscopy}

The FT-IR spectra of the macroinitiator Br-PEG-Br and the triblock oligomer $p$-TDFA-PEG- $p$-TDFA with molar ratio of [TDFA]/[Br-PEG-Br] to be 12:1 are shown in Figure 1. The absorption bands at 2963.7 and $2820.1 \mathrm{~cm}^{-1}$ correspond to the $\mathrm{C}-\mathrm{H}$ stretching of methyl and methylene group. The characteristic absorption peak of $1739.1 \mathrm{~cm}^{-1}$ belongs to carbonyl group $(\mathrm{C}=\mathrm{O})$ stretching vibration (Figure 1a). Compared with the spectrum of monomer TDFA, the characteristic band at $1650 \mathrm{~cm}^{-1}$ representing the stretching vibration of $\mathrm{C}=\mathrm{C}$ disappears in $p$-TDFA-PEG- $p$-TDFA, which indicates that the monomer TDFA disappeared during the polymerization. Moreover, the bands at $650.2,565.4$, and $530.0 \mathrm{~cm}^{-1}$ representing $\mathrm{C}-\mathrm{Br}$ are also clearly visible. Compared with the spectrum of the macroinitiator Br-PEG-Br, the triblock oligomer possesses an obvious absorption peak at 1126.7 to $1258.4 \mathrm{~cm}^{-1}$ which is ascribed to stretching vibration of C-F (Figure 1b).

Figure 2 exhibits the ${ }^{1} \mathrm{H}-\mathrm{NMR}$ spectra of the macroinitiator Br-PEG-Br and the triblock oligomer $p$-TDFA-PEG- $p$-TDFA whose molar ratio of [TDFA]/[Br-PEG-Br] is $12: 1$. The signal at $1.87 \mathrm{ppm}$ corresponds to the protons of $-\mathrm{C}\left(\mathrm{CH}_{3}\right)_{2}-\mathrm{Br}$ at the end group of macroinitiator, $3.68 \mathrm{ppm}$ belongs to the methylene protons of $-\mathrm{CH}_{2}-\mathrm{CH}_{2}$-O- (Figure 2a). As the number of methylene protons is much more than methyl protons, the signal of methylene protons would be much stronger than the latter. The ${ }^{1} \mathrm{H}$ NMR spectrum of the synthesized triblock oligomer $p$-TDFA-PEG- $p$-TDFA is shown in Figure $2 \mathrm{~b}$. The peaks at 1.26, 2.46 and $3.64 \mathrm{ppm}$ 
belongs to the protons of groups $-\mathrm{C}\left(\mathrm{CH}_{3}\right)_{2}-\mathrm{C}-,-\mathrm{CH}_{2} \mathrm{Br}$ and $-\mathrm{CH}_{2}-\mathrm{CH} \mathbf{H}_{2}-\mathrm{O}-$, respectively. The peaks at the chemical shifts of $4.36 \mathrm{ppm}$ are assigned both to the methine proton of - $\mathrm{CH}(\mathrm{COO})$ - and the methylene protons of $-\mathrm{CH}_{2} \mathrm{CH}_{2} \mathrm{CF}_{2}-$.

The triblock oligomer with an predictable $[\mathrm{TDFA}] /[\mathrm{Br}-\mathrm{PEG}-\mathrm{Br}]$ molar ratio of $12 / 1$, that can be calculated the actual molecular weight from the integration of the different groups of signals. Because of the molecular weight of the PEG is fixed (600), so the number of $-\mathrm{CH}_{2}-\mathrm{CH}_{2}-\mathrm{O}-$ can be calculated approximately equal to 13.5 . In the ${ }^{1} \mathrm{H}$ NMR spectrum, we can get the integration ratio between the methylene protons $\left(-\mathrm{CH}_{2}-\mathrm{CH}_{2}-\mathrm{O}-\right)$ and methylene protons $\left(-\mathrm{CH}_{2} \mathrm{Br}\right)$ is 1.46 . Thus we can calculate the number of $-\mathrm{CH}_{2} \mathrm{Br}$ approximately equal to 10 . This result approach the experimental results from GPC measurement.

Figure 3 shows the ${ }^{19} \mathrm{~F}$ NMR spectrum of $p$-TDFA-PEG- $p$-TDFA (molar ratio of [TDFA]/[Br-PEG-Br] is $12: 1)$. The peak at $-81.0 \mathrm{ppm}$ is assigned to the end $-\mathrm{CF}_{3}$ group, and the peaks at $-113.6 \mathrm{ppm},-122.0 \mathrm{ppm},-123.0 \mathrm{ppm},-123.6 \mathrm{ppm}$ and -126.2 ppm correspond to the $\mathrm{CF}_{2^{-}}$moiety of $\mathrm{CF}_{3} \mathrm{CF}_{2^{-}}, \mathrm{CF}_{3} \mathrm{CF}_{2} \mathrm{CF}_{2^{-}}, \mathrm{CF}_{3}\left(\mathrm{CF}_{2}\right)_{2} \mathrm{CF}_{2^{-}}$, $\mathrm{CF}_{3}\left(\mathrm{CF}_{2}\right)_{3} \mathrm{CF}_{2-}$ and $\mathrm{CF}_{3}\left(\mathrm{CF}_{2}\right)_{4} \mathrm{CF}_{2}$ - respectively. 


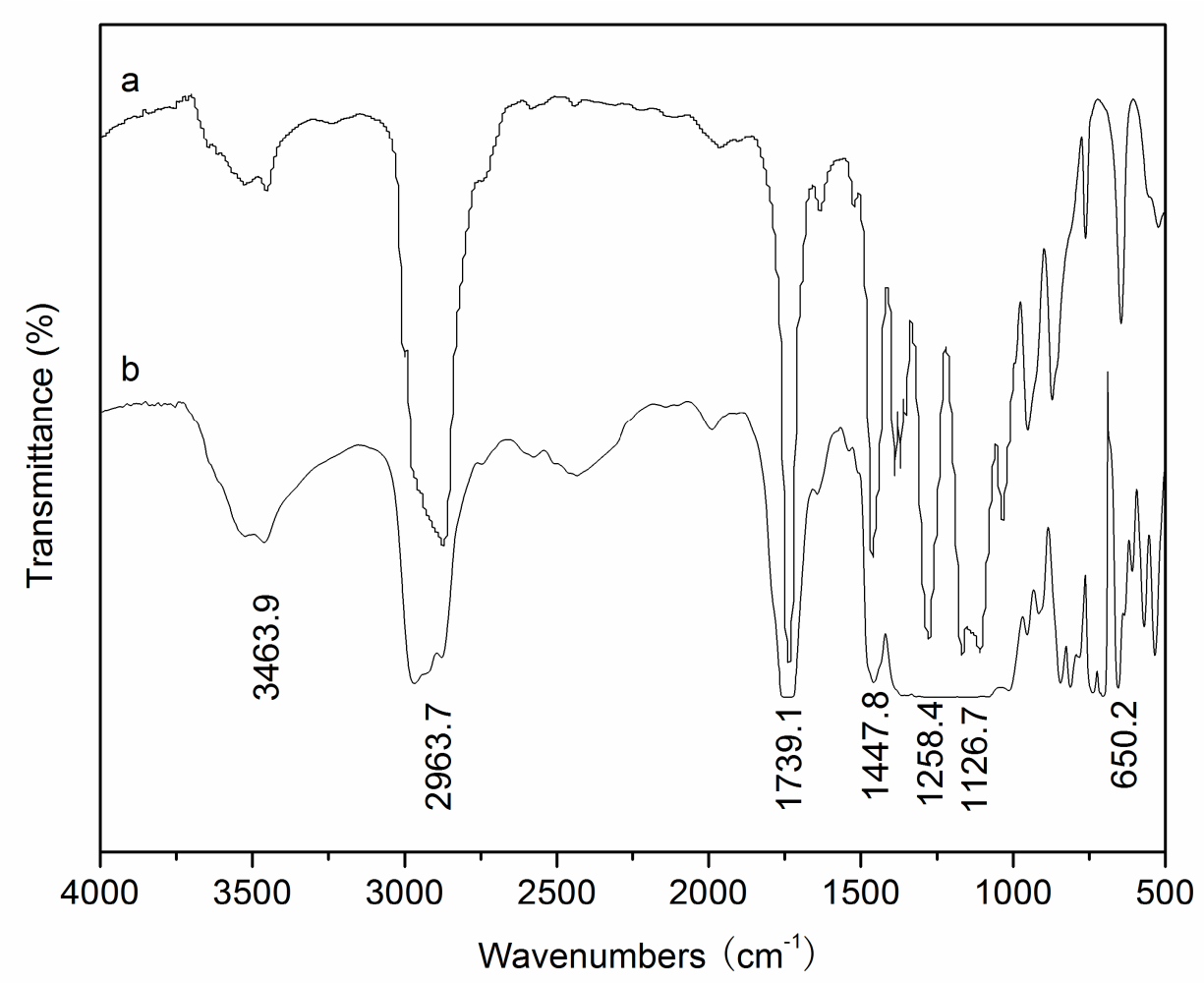

Figure 1. FT-IR spectra of macroinitiator (a) and triblock oligomer $p$-TDFA-PEG- $p$-TDFA with the molar ratio of [TDFA]/[Br-PEG-Br] is 12:1 (b) 

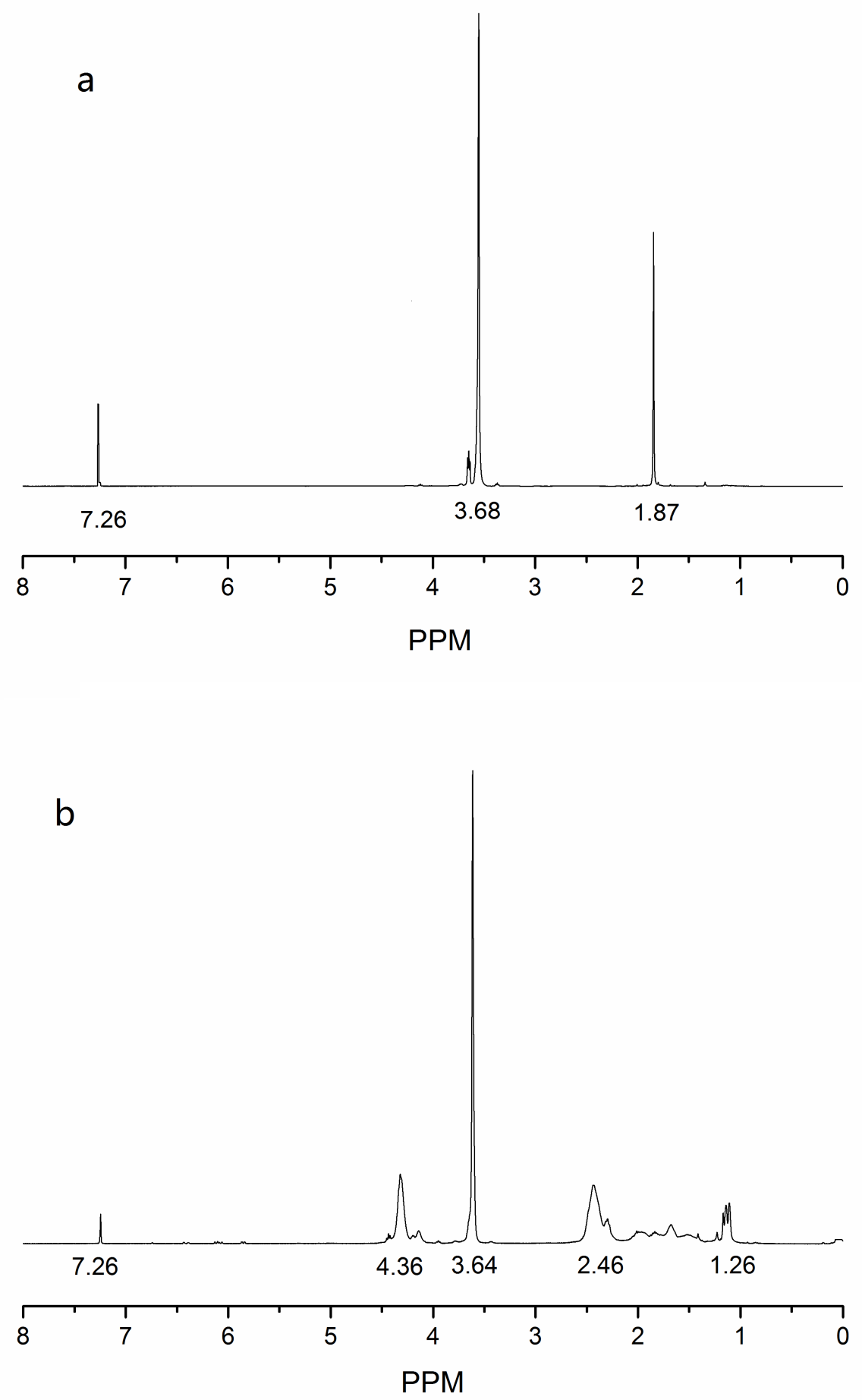

Figure 2. ${ }^{1} \mathrm{H}$ NMR spectra in $\mathrm{CDCl}_{3}$ for macroinitiator (a) and triblock oligomer $p$-TDFA-PEG- $p$-TDFA with the molar ratio of [TDFA]/[Br-PEG-Br] is 12:1 (b) 


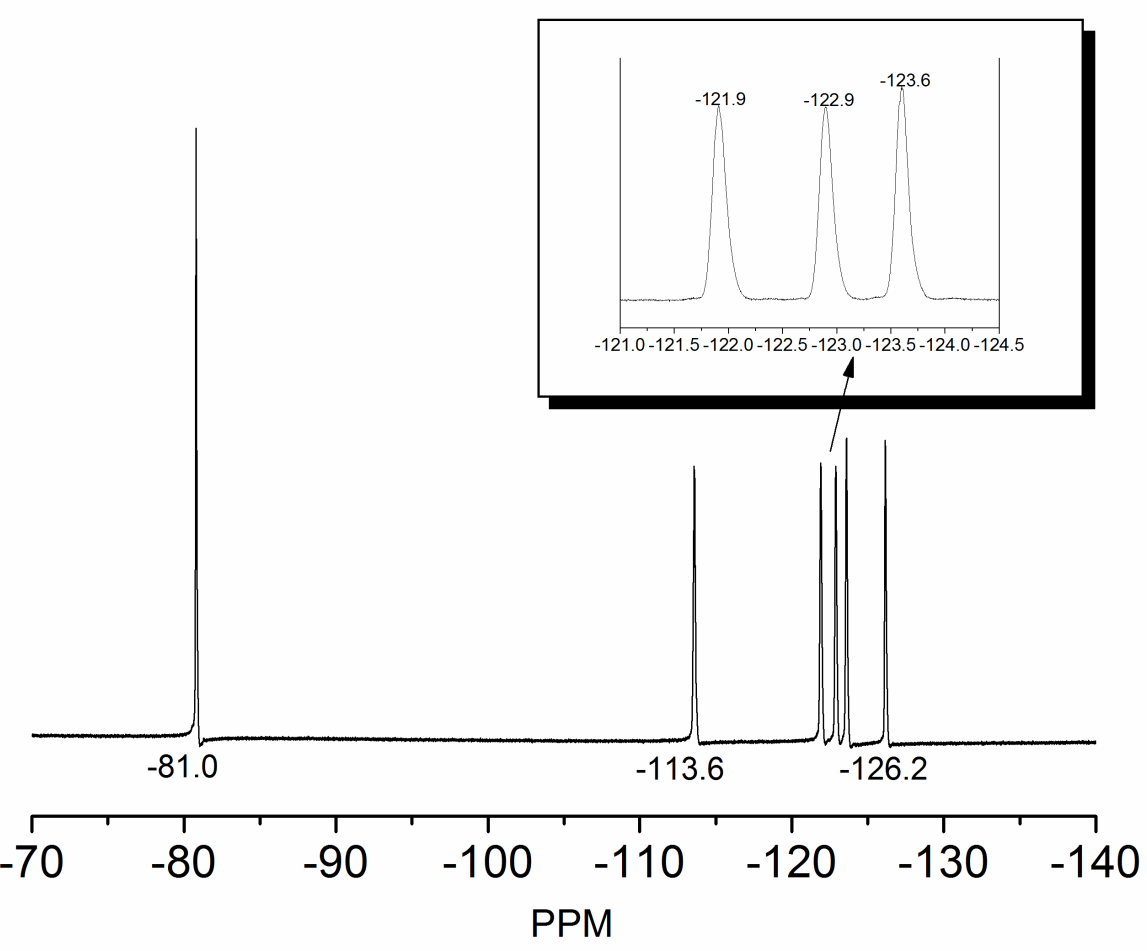

Figure 3. ${ }^{19} \mathrm{~F}$ NMR spectrum in $\mathrm{CDCl}_{3}$ for triblock oligomer $p$-TDFA-PEG- $p$-TDFA with the molar ratio of $[\mathrm{TDFA}] /[\mathrm{Br}-\mathrm{PEG}-\mathrm{Br}]$ is $12: 1$

\section{Gel permeation chromatography}

The molecular weight and molecular weight distribution of three triblock oligomers were determined by GPC using THF as an eluent. All the three oligomers represent the similar unimodal curve and a relatively low PDI (1.22, 1.33 and 1.33, respectively). The measured results of $p$-TDFA-PEG- $p$-TDFA are given in Table 1. From Table 1 we can see that the molecular weight from GPC test (Mn, GPC) closely meet the theoretically value (Mn, Theo.) predicted from the ratio of monomer/initiator $([\mathrm{M}] /[\mathrm{I}])$. It indicates that the $[\mathrm{M}] /[\mathrm{I}]$ can be used as a good control means of oligomer molecular weight. In other words, it is clear that the block copolymerization conforms 
to a living and controlled radical polymerization.

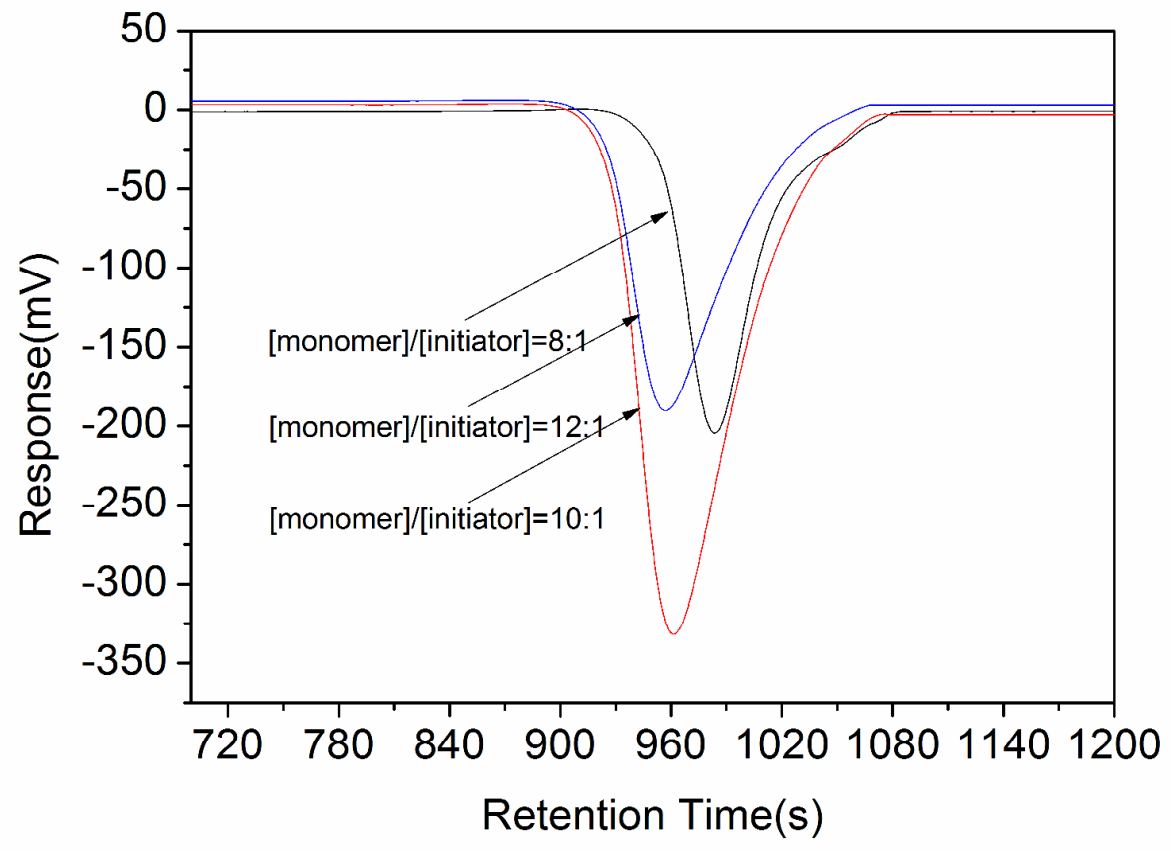

Figure 4. GPC traces of $p$-TDFA-PEG- $p$-TDFA prepared via ATRP of different molar ratios

Table 1. Molecular weight and molecular weight distribution of a series of block oligomers synthesized by ATRP

\begin{tabular}{cccccccc}
\hline Sample & {$[\mathrm{M}] /[\mathrm{I}]$} & $\mathrm{Mn}$ & $\mathrm{Mn}$ & $\mathrm{Mw}$ & & Conversion \\
& & $($ Theo. $)$ & $(\mathrm{GPC})$ & $(\mathrm{GPC})$ & & $(\%)$ \\
\hline$p$-TDFA-PEG- $p$-TDFA-1 & $8: 1$ & 3771 & 4274 & 5219 & 1.22 & 88.9 \\
& & & & & & \\
$p$-TDFA-PEG- $p$-TDFA-2 & $10: 1$ & 4829 & 5541 & 7405 & 1.33 & 95.1 \\
& & & & & & \\
$p$-TDFA-PEG- $p$-TDFA-3 & $12: 1$ & 5358 & 5931 & 7913 & 1.33 & 90.6 \\
\hline
\end{tabular}

\section{X-ray photoelectron spectroscopy}


The chemical compositions and chemical structures of the triblock oligomers were analyzed by X-ray photoelectron spectroscopy (XPS). The XPS wide-scanning spectra of $p$-TDFA-PEG- $p$-TDFA-3 were shown in Figure 5. As seen in Figure 5, the survey spectra of block oligomers showed the signals of C (284.8 eV), O (531.3 eV), and $\mathrm{F}(688.4 \mathrm{eV})$ agree with the chemical composition of amphiphilic fluorinated block oligomers $p$-TDFA-PEG- $p$-TDFA.

From the chemical composition of the oligomer showed in Table 2, we can know that the surface of the oligomer samples had a significant difference before and after annealing. Take $p$-TDFA-PEG- $p$-TDFA-3 for example, the mass concentration of $\mathrm{F}$ on the annealed surface was significantly higher than that of untreated one by increasing from $35.67 \%$ to $40.26 \%$. On the other hand, the $\mathrm{C}$, O percentage followed the opposite trend by decreasing from $51.48 \%, 12.85 \%$ to $47.05 \%, 12.69 \%$, respectively. These results demonstrated that the outermost surface of amphiphilic block oligomers was enriched by fluorine and thus lowered the surface free energy significantly. 


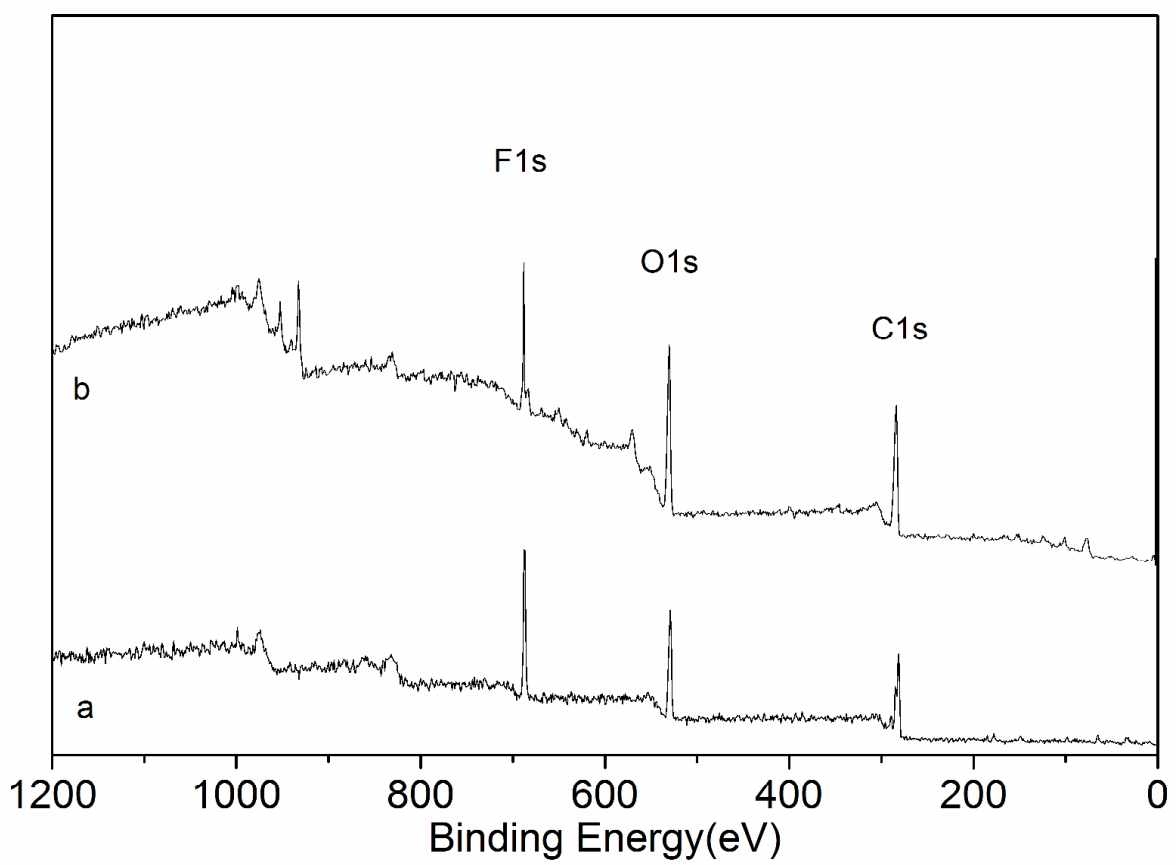

Figure 5. XPS spectra of triblock oligomer $p$-TDFA-PEG- $p$-TDFA-3 (molar ratio of [TDFA]/[Br-PEG-Br] is 12:1) before (a) and after (b) heat treatment (anneal at $160{ }^{\circ} \mathrm{C}$ for $30 \mathrm{~min}$, then, the treated samples were kept in a desiccator to equilibrate to room temperature for $24 \mathrm{~h}$ )

Table 2. XPS chemical compositions of block oligomers $p$-TDFA-PEG- $p$-TDFA before and after annealing process

\begin{tabular}{cccccc}
\hline \multirow{2}{*}{ Polymer film } & annealing & \multicolumn{4}{c}{ Mass concentration (\%) } \\
\cline { 3 - 5 } & & F & C & O \\
\hline$p$-TDFA-PEG- $p$-TDFA -1 & Before & 30.28 & 48.51 & 21.21 \\
& After & 33.69 & 46.16 & 20.15 \\
& & & & \\
& Before & 32.56 & 50.25 & 17.19 \\
& After & 34.88 & 47.76 & 17.36
\end{tabular}


$\begin{array}{lllll}p \text {-TDFA-PEG- } p \text {-TDFA-3 } & \text { Before } & 35.67 & 51.48 & 12.85\end{array}$

$\begin{array}{llll}\text { After } & 40.26 & 47.05 & 12.69\end{array}$

\section{Contact angle analysis}

The properties of materials are dependent on the surface structure and on the chemical composition of the outermost surface layer. ${ }^{53,54}$ Fluorinated polymers are well known for their low surface free energy. When the surface of a material is uniformly covered with $\mathrm{CF}_{2}$ or $\mathrm{CF}_{3}$ groups, a surface with very low energy can be achieved. In the present measurement, contact angles were used to evaluate the surface properties of triblock oligomers. Given the fluoroalkyl chains have the strong tendency to migrate and segregate under high temperatures, we measured the water contact angles (CA) of oligomer films before and after annealing and the data were summarized in Tables 3. The results showed that the water repellency of fluorinated oligomers was improved by annealing significantly, which confirmed the migration of fluoralkyl chains and the enrichment of fluorine onto the surface. This result has also been reported by some previous works. ${ }^{55,56}$ Moreover, the $p$-TDFA-PEG- $p$-TDFA-3 $\left(110.2^{\circ}\right)$ exhibits better water and oil repellency than $p$-TDFA-PEG- $p$-TDFA-2 $\left(108.6^{\circ}\right)$ and $p$-TDFA-PEG- $p$-TDFA-1 $\left(102.4^{\circ}\right)$ under the same condition, indicating that the incorporation of more fluorinated segments into the oligomers can significantly improve the water and oil repellency of materials.

Table 3. Water contact angles ${ }^{\mathrm{a}}$ of $p$-TDFA-PEG- $p$-TDFA before and after annealing process 


\begin{tabular}{ccc}
\hline Sample & \multicolumn{2}{c}{ Contact angle $\left( \pm 2^{\circ}\right)$} \\
\cline { 2 - 3 } & Before annealing & After annealing \\
\hline$p$-TDFA-PEG- $p$-TDFA-1 & 81.8 & 102.4 \\
$p$-TDFA-PEG- $p$-TDFA-2 & 87.2 & 108.6 \\
$p$-TDFA-PEG- $p$-TDFA-3 & 95.1 & 110.2 \\
\hline
\end{tabular}

${ }^{a}$ The contact angles were measured when drops of water dripping on the surfaces in $30 \mathrm{~s}$.

\section{Surface morphology analysis by AFM}

The block oligomers contain both hydrophilic PEG block and hydrophobic fluorinated segments. These two segments are of significantly different polarities and meanwhile mutual chemical incompatibility. These features resulted in an interesting surface with microphase structure and rough morphological.

AFM images of the oligomer surfaces were showed in Figure 6. For the three oligomers, after heated at $120{ }^{\circ} \mathrm{C}$ for $60 \mathrm{~min}$, the film surfaces possess obvious uneven morphology, together with a great deal of randomly distributed peaks (Picture b, d, and f). This morphological feature can be apparently evidenced by the 3-D images (Picture a, c, and e) as the surfaces were all inhomogeneous and with plenty of sharp peaks. As we all know, the fluoroalkyl chains have the inherent properties of migration and segregation under high temperatures. Therefore, the fluoroalkyl chains prefer to migrate to the air-polymer interface and occupy the outmost surface during the annealing process. ${ }^{57,58}$ Obviously, these sharp peaks in 3-D image or the brighter 
areas in 2-D image, demonstrates the aggregation of fluorinated chains, while the darker areas are corresponding to the soft segments of PEG domain. The appearance of these sharp peaks with a certain orientation indicated that the microphase separation of the surface based on the migrating of fluoroalkyl groups has occurred and thus generate the more hydrophobic surface. ${ }^{59}$
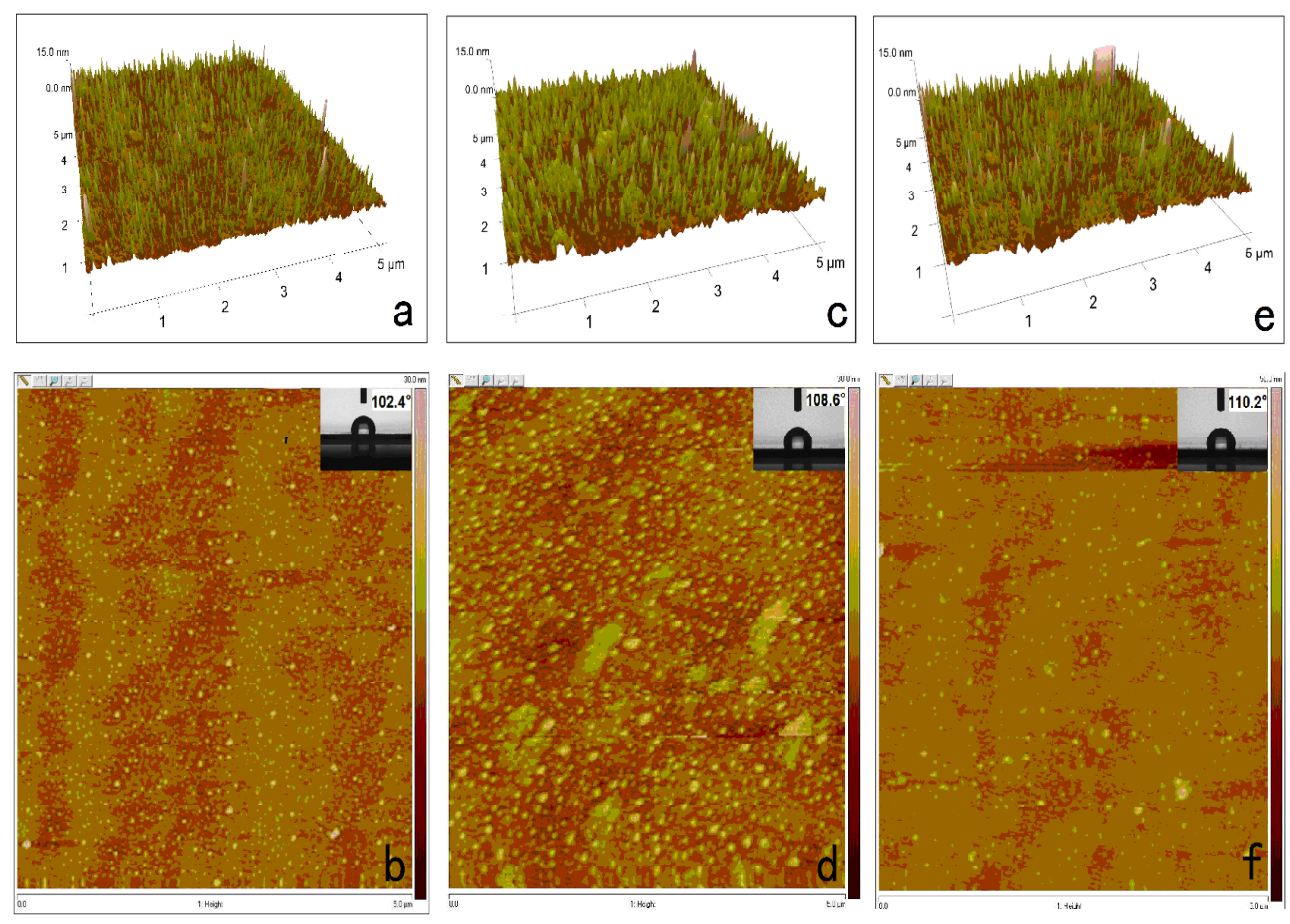

Figure 6. AFM phase images of copolymers: (a) and (b) corresponding to $p$-TDFA-PEG- $p$-TDFA-1, (c) and (d) corresponding to $p$-TDFA-PEG- $p$-TDFA-2, (e) and (f) corresponding to $p$-TDFA-PEG- $p$-TDFA-3, taken in air (tapping mode)

\section{CONCLUSIONS}

In summary, after these comprehensive characterization analysis, FT-IR, ${ }^{1} \mathrm{H}$ NMR and ${ }^{19} \mathrm{~F}$ NMR, we could believe that this novel amphiphilic triblock oligomers namely $p$-TDFA-PEG- $p$-TDFA, which composed of PEG and fluorinated segments 
were synthesized successfully. The molecular weight distribution of the triblock oligomers was measured to be narrow, confirming the advantage of the ATRP technology by GPC. The change of the chemical elements content of oligomer film surfaces before and after heat treatment was tested by XPS and the migration of fluoroalkyl groups was identified. It was demonstrated that the annealing process promoted the segregation of fluoroalkyl chains toward the surface and reduced the surface free energy significantly. This microphase separation structure of the surface after heat treatment has been further confirmed by AFM. Finally, the highest CA of sample 1,2 , and 3 were $102.4^{\circ}, 108.6^{\circ}$, and $110.2^{\circ}$, respectively. It showed that the more fluoroalkyl block was introduced and bonded to the ending segments of PEG, the lower surface free energy of the block oligomer could be.

\section{ACKNOWLEDGMENTS}

We gratefully acknowledge the financial supports by the National Natural Science Foundation of China (No. 51673137, 51273140), Jiangsu Overseas Research \& Training Program for University Prominent Young \& Middle-aged Teachers and Presidents, and the Project Funded by the Priority Academic Program Development of Jiangsu Higher Education Institutions.

\section{REFERENCES}

1 Hucknall, A.; Rangarajan, S.; Chilkoti, A. Adv. Mater. 2009, 21, 2441.

2 Ma, H.; Wells, M.; Beebe, T. P.; Chilkoti, A. Adv. Funct. Mater. 2006, 16, 640.

3 Jiang, S.; Cao, Z. Adv. Mater. 2010, 22, 920. 
4 Luzon, M.; Boyer, C.; Peinado, C.; Corrales, C.; Whittaker ,T. M. J. Polym. Sci.

Part A: Polym. Chem. 2010, 48, 2783.

5 Chen, S. F.; Jiang, S. Y. Adv. Mater. 2008, 20, 335.

6 Yang, W.; Zhu, L. Q.; Chen, Y.C. J. Fluorine Chem. 2014, 157, 35.

7 Yan, Z. L.; Liu, W. Q.; Gao, N.; Ma, Z. Q.; Han, M. J. J. Fluorine Chem. 2013, 147, 49.

8 Yao, W. Q.; Li, Y. J.; Huang, X. Y. Polymer 2014, 55, 6197.

9 Yan, Z. L.; Liu, W. Q.; Gao, N.; Wang, H. L.; Su, K. Appl. Surf. Sci. 2013, 284, 683.

10 Koiry, B. Q.; Klok, H. A.; Singha, N. K. J. Fluorine Chem. 2014, 165, 109.

11 Miao, H.; Bao, F. F.; Cheng, L. L.; Shi, W. F. J. Fluorine Chem. 2010, 131, 1356.

12 Chen, L. J.; Shi, H. X.; Wu, H. K.; Xiang, J. O. J. Fluorine Chem. 2010, 131, 731.

13 Wu, L.; Jasinski, J.; Krishnan, S. J. Appl. Polym. Sci. 2012, 124, 2154.

14 Thanawala, S. K.; Chaudhury, M. K. Langmuir 2000, 16, 1256.

15 Koberstein, J. T. J. Polym. Sci. Part B: Polym. Phys. 2004, 42, 2942.

16 Krishnan, S.; Ward, R. J.; Hexemer, A.; Sohn, K. E.; Lee, K. L. Langmuir 2006, 22, 11255.

17 Krishnan, S.; Paik, M. Y.; Ober, C. K.; Martinelli, E.; Galli G. Macromolecules 2010, 43, 4733.

18 Colak, S.; Tew, G. N. Biomacromolecules 2012, 13, 1233.

19 Chang, Y.; Prange, R.; Allcock, H. R.; Lee, S. C.; Kim, C. Macromolecules 2002, 35,8556 . 
20 Masci, G.; Bontempo, D.; Tiso, N.; Diociaiuti, M. Macromolecules 2004, 37, 4464.

21 Bouilhac, C.; Cloutet, E.; Taton, D.; Deffieux, A. J. Polym. Sci. Part A: Polym. Chem. 2009, 47, 197.

22 Pottier, C.; Morandi, G.; Rihouey, C.; Dulong, V.; Picton, L.; Cerf, D. L. J. Polym. Sci. Part B: Polym. Phys. 2016, 54, 1507.

23 Lohmeijer, B. G. G.; Schubert, U. S. J. Polym. Sci. Part A: Polym. Chem. 2004, 42, 4016.

24 Gopalan, P.; Li, X.; Li, M.; Ober, C. K.; Gonzales, C. P.; Hawker, C. J. J. Polym. Sci. Part A: Polym. Chem. 2003, 41, 3640.

25 Matsuno, R.; Yamamoto, K.; Otsuka, H.; Takahara, A. Macromolecules 2004, 37, 2203.

26 Huang, J. Y.; Pintauer, T.; Matyjaszewski, K. J. Polym. Sci. Part A: Polym. Chem. 2004, 42,3285 .

27 Lutz, J. F.; Jahed, N.; Matyjaszewski, K. J. Polym. Sci. Part A: Polym. Chem. 2004, 42, 1939.

28 Sarbu, T.; Lin, K. Y.; Ell, J.; Siegwart, D. J.; Spanswick, J.; Matyjaszewski, K. Macromolecules 2004, 37, 3120.

29 Hao, X. J.; Nilsson, C.; Jesberger, M.; Stenzel, M. H.; Malmstrom, E.; Davis, T. P.; Ostmark, E.; Barner, K. C. J. Polym. Sci. Part A: Polym. Chem. 2004, 42, 5877.

30 Hong, C. Y.; You, Y. Z.; Pan, C. Y. J. Polym. Sci. Part A: Polym. Chem. 2004, 42, 4873.

31 Wang, G. W.; Schmitt, M.; Wang, Z. Y.; Lee, B. J.; Pan, X. C.; Fu, L. Y.; Yan, J. J.; 
Li, S. P.; Xie, G. J.; Bockstaller, M. R.; Matyjaszewski, K. Macromolecules 2016, 49, 8605 .

32 Schilli, C. M.; Zhang, M. F.; Rizzardo, E.; Thang, S. H.; Chong,Y. K. Macromolecules 2004, 37, 7861.

33 Shen, D.; Huang, Y. Polymer 2004, 45, 7091.

34 Demirelli, K.; Kurt, A.; Coskun, M. F.; Coskun, M. J. Macromol. Sci., 2006 43, 573.

35 Matyjaszewski, K.; Teodorescu, M.; Miller, P. J.; Peterson, M. L. J. Polym. Sci. Part A: Polym. Chem. 2000, 38, 2440.

36 Demirelli, K.; Kurt, A.; Coskun, M. Eur. Polym. J. 2004, 40, 451.

37 Andreas, M.; Scott, G. G.; Krzysztof, M. Macromolecules 1998, 31, 6046.

38 Qiu, J.; Charleux, B.; Matyjaszewski, K. Prog. Polym. Sci. 2001, 26, 2083.

39 Braunecker,W. A.; Matyjaszewski, K. Prog. Polym. Sci. 2007, 32, 93.

40 Dimitrov, I.; Trzebicka, B.; Dworak, A.; Tsvetanov, C. B. Prog. Polym. Sci. 2007, $32,1275$.

41 Matyjaszewski, K.; Patten, T. E.; Xia, J. J. Am. Chem. Soc. 1997, 119, 674.

42 Jakubowski, W.; Matyjaszewski, K. Macromol. Symp. 2006, 240, 213.

43 Messman, J. M.; Scheuer, A. D.; Storey, R. F. Polymer 2005, 46, 3628.

44 Liaw, D. J.; Huang, C. C.; Ju, J. Y. J. Polym. Sci. Part A: Polym. Chem. 2006, 44, 3382.

45 Wolf, F. F.; Friedemann, N.; Frey, H. Macromolecules 2009, 42, 5622.

46 Sha, K.; Li, D. S.; Li, Y. P.; Liu, X. T.; Wang, S. W. J. Polym. Sci. Part A: Polym. 
Chem. 2007, 45, 5037.

47 Coumes, F.; Beaute, L.; Domurado, D.; Li, S.; Lecommandoux, S.; Coudane, J.;

Darcos, V. Royal Society of Chemistry 2016, 6, 53370.

48 Li, P. P.; Li, Z. Y.; Huang, J. L. Polymer 2007, 48, 1557.

49 Zhang, Y. F.; Li, C. H.; Liu, S. Y. J. Polym. Sci. Part A: Polym. Chem. 2009, 47, 3066.

50 Gou, P. F.; Zhu, W. P.; Zhu, N.; Shen, Z. Q. Sci. Part A: Polym. Chem. 2009, 47, 2905.

51 Ding, H. J.; Park, S. W.; Zhong, M. J.; Pan, X. C.; Pietrasik, J.; Bettinger, C. J.; Matyjaszewski, K. Macromolecules 2016, 49, 6752.

52 Nie, J. J.; Zhao, W. Y.; Hu, H.; Yu, B. R.; Xu, F. J. ACS Appl. Master Interf. 2016, 8,8376 .

53 Borkar, S.; Jankova, K.; Siesler, H. W.; Hvilsted, S. Macromolecules 2004, 37, 788.

54 Ha, J. W.; Park, I. J.; Lee, S. B. Macromolecules 2005, 38, 736.

55 Sun, P.; Horton, J. H. Appl. Surf. Sci. 2013, 271, 344.

56 Ghosh, N.; Singh, A. V.; Vaidys, A. A. ACS Appl. Mater. Interf. 2013, 5, 8869.

57 An, Q. F.; Xu, W.; Hao, L. F.; Li, L.; Wu, S. L. J. Appl. Polym. Sci. 2013, 127, 1519.

58 Xiong, S. D.; Guo, X. L.; Li, L.; Wu, S. L.; Chu, P. K.; Xu, Z. S. J. Fluorine. Chem. 2010, 131, 417.

59 Woodward, I.; Schofield, W. C. E.; Roucoules, V.; Badyal, J. P. S. Langmuir 2003, 
19, 3432 . 